\title{
Assessing the effect of a Cognitive Behaviour Therapy (CBT)-based workshop on work- related rumination, fatigue and sleep
}

\author{
Dawn Querstret ${ }^{1}$, Mark Cropley ${ }^{1}$, Pieter Kruger $^{2}$, Richard Heron ${ }^{3}$ \\ ${ }^{1}$ University of Surrey, ${ }^{2}$ LPP Consulting, ${ }^{3}$ BP p.l.c.
}

Correspondence concerning the article should be addressed to Dr. Dawn Querstret: dawn.querstret@surrey.ac.uk.

Citation: Querstret, D., Cropley, M., Kruger, P., \& Heron, R. (2016). Assessing the effect of a Cognitive Behaviour Therapy (CBT)-based workshop on work-related rumination, fatigue, and sleep. European Journal of Work and Organizational Psychology, 25(1), 50-67. doi: 10.1080/1359432X.2015.1015516. 


\begin{abstract}
This quasi-experimental longitudinal study assessed the effect of a one-day Cognitive Behaviour Therapy (CBT)-based workshop on work-related rumination, chronic fatigue and sleep quality. We hypothesised that participants who attended the workshop would report lower levels of affective work-related rumination and chronic fatigue and improved sleep quality, at follow-up, six months after workshop completion. Two hundred and twenty seven participants took part in the study, with 102 participants attending a one-day workshop delivered in their place of work. Participants completed an online questionnaire at two timepoints, with follow-up occurring 6 months after initial survey completion. Results showed that participants who took part in the CBT workshop reported significantly lower levels of affective rumination $(\mathrm{p}=.03)$ and chronic fatigue $(\mathrm{p}=.003)$, at follow-up in comparison to individuals who did not attend the workshop; however there were no significant differences between the groups in self-reported sleep quality $(p=.06)$. A combination of more effective recovery both at work and outside of work may explain the reductions in both affective rumination and fatigue over time. This study adds to the recovery from work literature by providing initial support for a one-day CBT-based workshop delivered in the workplace.
\end{abstract}

Keywords: rumination, fatigue, Cognitive Behaviour Therapy, CBT, workplace intervention. 
Assessing the effect of a Cognitive Behaviour Therapy (CBT)-based workshop on workrelated rumination, fatigue and sleep.

\section{Introduction}

The relationship between work-related stress and ill health is undoubtedly underpinned by many contributing factors; however, perhaps the most critical mechanism is inadequate psychological and physical recovery from work (Fritz, Sonnentag, Spector \& McInroe, 2010). When people go to work, they are confronted with many different kinds of physical, cognitive and emotional demands. In order to deal with these demands people must expend physical, emotional and cognitive energy (Zijlstra \& Sonnentag, 2006). Using energy in this way results in fatigue at the end of the working day and people's 'resources' (physical and mental) become depleted (Meijman, Mulder, \& van Dormolen, 1992). Rest is then required in order for those depleted resources to be replenished. This process of replenishment is called 'recovery' (often referred to as 'recharging one's batteries'), and the anticipated effect of this recovery process is the reduction of fatigue and associated health complaints (Zijlstra \& Sonnentag, 2006).

Recovery from work is often conceptualised by two distinct, but compatible theories: conservation of resources theory (COR; Hobfoll, 1998) and the effort-recovery theory (Meijman \& Mulder, 1998). According to Hobfoll's COR theory, people are motivated to retain, protect and replenish various personal resources which are characterised as external (e.g., financial, material, social support) and internal (e.g., energy levels, perceptions of selfworth). When these resources are under threat, are lost, or fail to be replenished after a period of resource investment the individual may experience stress and resources that are lost or diminished during work time then need to be replenished during periods of rest (Demerouti, Bakker, Geurts, \& Taris, 2009; Eden, 2001; Fritz \& Sonnentag, 2006; Sonnentag, 2011). The effort-recovery theory suggests that in order for resources - which have been diminished through the demands of work to be replenished - the individual must refrain from placing 
further demands on systems which were taxed during work time (Meijman \& Mulder, 1998). For example, if the individual has a job which is very cognitively demanding (e.g., complex computer modelling), according to the effort-recovery theory they should avoid engaging in activity (when they get home) which is also cognitively demanding; instead, they should engage in activities that use different resource systems (e.g., physical exercise) or that do not require much cognitive effort (e.g., watching television). If individuals cannot adequately recover when they are not working, they will be operating with reduced psychological and physiological resources and will need to make more effort in order to maintain their performance in their next work shift. As a consequence they will have an even greater need for recovery, resulting in 'recovery debt' (Geurts \& Sonnetag, 2006); with a spiral of resource loss resulting in burnout, fatigue and other health complaints (Eden, 2001; Hobfoll \& Shirom, 1993). These two theories complement one another in that the COR theory suggests people are motivated to retain and replenish their resources; and the effort-recovery theory purports that in order for this replenishment to take place, people should refrain from taxing the same systems they use at work when they are at home.

Inadequate recovery may in part be due to the increasing difficulty individuals have in separating work from non-work time. Over the past decade management practices have led to an intensification of work and this, paired with technological advances, means that many employees are 'taking their work home with them' (e.g., with constant connectivity and access to emails at home) (Park, Fritz, \& Jex, 2011). This may make the boundary between work and non-work time much more difficult for individuals to establish resulting in compromised space for recovery activities and processes to take place (Park, et al., 2011; Cropley \& Millward, 2009). Furthermore, some aspects of the work environment threaten or deplete an individual's personal resources. For example, if employees are working considerably longer hours they will not only face a depletion of resources whilst at work, they will also have less time for recovery, and fewer opportunities to invest in valuable sources of 
social support outside of the workplace (Flaxman, Menard, Bond, \& Kinman, 2012). In many occupations demands associated with work are primarily of a cognitive nature (e.g., responsibility, information processing, project management, etc.), and approximately half of the working population complains of increasing levels of 'work pressure' (Paoli \& Merllie, 2001).

Optimising recovery is an important accomplishment because research has shown that inadequate recovery from the demands of work is associated with poor health outcomes including: elevated risk of cardiovascular disease (Suadicani, Hein, \& Gyntelberg, 1993); negative mood states (Pravettoni, Cropley, Leotta, \& Bagnara, 2007); compromised sleep (Akerstedt, Fredlund, Gillberg, \& Jansson, 2002; Nylen, Melin, \& Laflamme, 2007); and increased levels of fatigue (Cropley, Dijk, \& Stanley, 2006; Querstret \& Cropley, 2012). Periods of respite from the demands of work are particularly important because they represent the main avenue for the replenishment of resources which have been depleted through work (Demerouti, et al., 2009; Eden, 2001; Fritz \& Sonnentag, 2006; Sonnentag, 2001). Some recovery from stress and fatigue can occur at work, for example, during meal breaks, while waiting for task reassignment, or during other spontaneous work breaks (Sluiter, Frings-Dresen, Meijman, \& van der Beek, 2000); however, the majority of recovery from work-related stress and fatigue takes place during non-work time, between work shifts (Winwood, Bakker \& Winefield, 2007). This is not surprising because this period represents the most extensive opportunity for the reversal of depleted physical, psychological and emotional resources (e.g., through sleep).

The effort-recovery (Meijman \& Mulder, 1998) and COR (Hobfoll, 1998) theories have helped to identify aspects of impaired wellbeing that are likely to stem from inadequate recovery. Emotional exhaustion and fatigue are two of the most frequently examined outcomes in recovery from work research (Flaxman, et al., 2012). In the context of the effortrecovery and COR theories, work-related emotional exhaustion (which is a central feature of 
burnout) and work-related fatigue have been highlighted as load reactions which will be maintained or exacerbated by inadequate recovery from work-related stress; and research has established associations between poorer respite experiences and elevated levels of both constructs (see, e.g., de Bloom, Kompier, Geurts, de Weerth, Taris, \& Sonnentag, 2009; Eden, 2001; Etzion, 2003; Westman \& Etzion, 2001; de Bloom, Geurts, Taris, Sonnentag, de Weerth, \& Kompier, 2010; Demerouti, et al., 2009; Sonnentag \& Bayer, 2005).

\section{Fatigue}

Fatigue, driven by increased psychophysiological workload and reduced sleep, has been recognised as a major consequence of increased work intensity (Harma, Kompier, \& Vahtera, 2006). The term fatigue is used in many different ways and there is no single accepted definition; however, the literature consistently distinguishes between acute and chronic fatigue. Acute fatigue is short-lived and signals to the individual that they need to make space for recovery. In the work context, acute fatigue - or 'need for recovery' represents the sense of urgency that people feel to take a break from work demands (Kinnunen, Feldt, Siltaloppi, \& Sonnentag, 2011). In contrast, chronic fatigue is persistent and could be considered to be the consequence of continuing to tax already overburdened systems (Winwood et al., 2007). Fatigue that is acute in nature and modifiable by rest and/or by task moderation is generally adaptive and not inevitably stressful (Winwood, Lushington, \& Winefield, 2006); however, persisting with activity while already fatigued - because of perceived internal or external pressures - may be experienced as stressful (Aaron \& Buchwald, 2001; Baker, Mendenhall, Simbartl, Magan \& Steinberg, 1997; Bultmann, Kant, Kasl, Schroer, Swaen \& van den Brandt, 2002). Chronic fatigue could be considered the consequence of continuing to tax already overburdened systems; therefore, in the context of the effort-recovery theory (Meijman \& Mulder, 1998) individuals experiencing acute fatigue who do not make time for recovery may develop more persistent (chronic) fatigue.

Individuals who are chronically fatigued often are unable to continue with activity and this is 
associated with apathy and a lack of motivation. In the occupational literature, chronic fatigue is closely related to emotional exhaustion (a component of occupational burnout) which is not relieved by daily or weekly rest (Maslach, Schaufeli \& Leiter, 2001; Schaufeli \& Ensmann, 1998). There is no agreement in the literature regarding how to differentiate between acute (short-term) fatigue, and chronic (persistent or long-term) fatigue. Indeed, the difference between these two forms of fatigue appears to be an artefact of the language used in different fatigue measures. For this reason, researchers often use the term 'fatigue' in a more general sense and it is then the purview of the reader to establish the specifics of the construct.

Levels of reported work-related fatigue appear to be consistent across different geographic and cultural contexts. For example, in Europe research suggests that between 11 and $30 \%$ of workers are affected by work-related fatigue (Akerstedt et al., 2002; Houtman, 1997; Loge, Ekeberg, \& Kaasa, 1998; Bultmann, Kant, van Amelsvoort, van den Brandt, \& Kasl, 2001); and in the USA both men (14.3\%) and women (20.4\%) report fatigue which is work-related (Chen, 1986). Increased levels of fatigue in the work environment can have serious consequences; for example, work-related fatigue in nurses has been linked to increased medication errors, an increase in work-related injuries, decreased productivity and cognitive impairment (Kunert, King, \& Kolkhorst, 2007). Research has shown that psychomotor and cognitive functioning, mood and motivation are affected by fatigue (Williamson, Lombardi, Folkard, Stutts, Courtney \& Connor, 2011). Furthermore, fatigue has been linked to increased reaction times, decreased vigilance (ability to detect and react to unexpected events), memory impairment, compromised decision making, and reductions in information processing capacity (Lyznicki, Doege, Davis, \& Williams, 1998). Given the real world consequences of work-related fatigue, it is important to identify possible causal mechanisms and to develop interventions which may aid recovery from work. Possibly the most important mechanism to prevent fatigue accumulating is sleep, arguably our primary restorative process. 


\section{Sleep}

The value of good quality sleep for effective recovery is well established. The brain requires sleep in order for energy stores to be restored (Porkka-Heiskanen, Kalinchuk, Alanko, Urrila, \& Stenberg, 2003); and research has shown an association between chronically poor sleep and a multitude of different health impairments, such as self-reported coronary heart disease (Schwartz, Anderson, Cole, Cornoni-Huntley, Hays, \& Blazer, 1999), gastrointestinal problems, high blood pressure, neurological disorders (Taylor, Mallory, Lichstein, Durrence, Riedel, \& Bush, 2007), cardiovascular disease (CVD), diabetes, obesity and depression (Akerstedt, 2006). Performance is also negatively impacted by sleep loss and sleep disturbance; and sleep loss can result in increased fatigue, mood changes, and impairment of the immune system (Harrison \& Horne, 1999; Rogers, Szuba, Staab, Evans, \& Dinges, 2001). One of the consequences of sleep disturbance is sleepiness during activity periods which can result in an increase in work-related accidents (Lauber, \& Kayten, 1988), with potential work-related injuries and loss of productivity (Kantermann, Juda, Vetter, \& Roenneberg, 2010). Furthermore, sleep debt and problems getting to sleep are known to compromise memory consolidation (Karni \& Sagi, 1993) and decrease attention, performance and mood (Dinges, Pack, Williams, Gillen, Powell, Ott, et al., 1997).

Having sufficient time between work shifts for sleeping does not necessarily mean that adequate restorative sleep will occur (Winwood et al., 2007); and the reality for many workers with stressful occupations is that sleep quality is frequently below that which is required, due to the persistence of stress-response brain arousal in non-work time (Akerstedt et al., 2002; Linton, 2004; Strine, \& Chapman, 2005). While there are several cross-sectional studies (see, e.g., Akerstedt, et al., 2002; Geiger-Brown, et al., 2011), and a few longitudinal studies (see, e.g., Burgard \& Ailshire, 2009; de Lange, Kompier, Taris, Geurts, Beckers, Houtman, et al., 2009) demonstrating a relationship between work-related stress and sleep, the mechanism/s by which occupational stress influences sleep remain uncertain. However, 
the sleep literature agrees that one of the factors thought to interfere with sleep is perseverative thinking (e.g., rumination, worry), with self-reported sleep disturbance showing a strong relationship with work-related worries and rumination (Akerstedt et al., 2002).

Furthermore, a survey on sleep behavior found that $17 \%$ of a representative sample (working in the U.K.) reported that they have sleep problems and attributed these problems to worrying about work (Groeger, Zijlstra, \& Dijk, 2004).

\section{Work-related rumination}

Where good quality sleep may aid recovery from work (e.g., by reducing fatigue), a mechanism which may interfere with recovery processes (e.g., by interfering with sleep) is work-related rumination. Work-related rumination is a relatively new construct; therefore, the majority of research in the occupational literature regarding thinking about work in non-work time has concentrated on assessing the impact of adequately 'psychologically detaching' from work (Sonnentag \& Bayer, 2005); that is, not thinking about work outside of work. In jobs which are more physically (than psychologically) demanding, it is relatively easy to see when a stressor ends such that recovery processes can begin however this is not so simple for jobs which are psychologically taxing (Sonnentag, 2011). For psychological stressors (e.g., high workload, social conflict at work, role ambiguity) it is more difficult to determine when the demands exerted by the stressor cease to place demands on the individual. Specifically, the demands of these types of stressors may be maintained outside of work if the individual continues to think about them when they are no longer at work (Brosschot, et al., 2006). Therefore, it is not sufficient to simply be away from the working environment, the individual must also disconnect (or detach) from work mentally (Sonnentag, 2011).

Work-related rumination refers to the tendency for some people to think about ('ruminate' about or ponder over) work-related issues and events outside of work (Cropley \& Zijlstra, 2011). There are many triggers for work-related rumination. Some people think about uncompleted tasks, others ruminate about a problem that needs to be solved, and still 
others think about relationship issues with colleagues or negative events at work (Querstret \& Cropley, 2012). People don't just think about events or issues that have occurred in the past, but they also ruminate anticipatively (or worry), about upcoming work-related events/demands and issues (Cropley \& Zijlstra, 2011); therefore work-related rumination may possess elements of both rumination (traditionally characterised as past-focused) and worry (traditionally characterised as future-focused) (Flaxman, Bond, \& Livheim, 2013).There is a growing body of research showing that psychological detachment from work (i.e., not thinking about work outside of work hours) is necessary for optimal recovery to occur (Sonnentag \& Bayer, 2005; Sonnentag \& Kruel, 2006; Geurts \& Sonnentag, 2006). For example, Kinnunen et al. (2011) showed that inadequate psychological detachment fully mediated the relationship between job demands and fatigue (in the form of need-for-recovery and exhaustion); and poor psychological detachment has also been shown to predict increased need for recovery and job exhaustion (Siltaloppi, Kinnunen, \& Feldt, 2009). Furthermore, Akerstedt, Knutsson, Westerholm, Theorell, Alfredsson \& Kecklund (2004) showed that an inability to mentally switch off after work partially accounts for the effects of high work demands on disturbed sleep; and Berset, Elfering, Luthy, Luthi \& Semmer (2010) suggested that the relationship between work demands and sleep was mediated by rumination. Research suggests that work-related rumination is common with a large proportion of the population ruminating at one time or another (Gallie, White, Cheng, \& Tomlinson, 1998); furthermore, it appears that rumination may be on the rise (Felstead, Gallie, \& Green, 2002).

Rumination as a construct has been researched in clinical and health settings for many years, with results implicating rumination in the development of a number of psychological disorders, e.g., depression and anxiety (Lyubomirsky, Caldwell, \& Nolen-Hoeksema, 1998; Mellings \& Alden, 2000). Rumination in these settings has also been associated with intrusive off-task thoughts (Sarason, Pierce, \& Sarason, 1996), increased reporting of physical symptoms (Hazlett \& Haynes, 1992), diminished feelings of control and a sense of 
helplessness (Lyubomirsky, Kasri, \& Zehm, 2003). In a comprehensive review, Brosschot, et al. (2006) suggested that various forms of rumination may be underpinned by a shared cognitive process. This process is labelled 'perseverative cognition' and is defined as: "the repeated or chronic activation of the cognitive representation of one or more psychological stressors" (Brosschot, et al., 2006, p.114). Essentially, whilst the content of this cognitive process may be different (e.g., on depressive symptoms in depressive rumination or on workrelated issues in work-related rumination), and the focus of this process may also be different (e.g., on future versus past events/issues), the actual underlying cognitive process is the same, that of perseverative cognition (Brosschot et al., 2006). Therefore, in line with the perseverative cognitions hypothesis (Brosschot, et al., 2006), it is possible that work-related rumination may extend work-related demands outside of work time because the continued cognitive representation of these demands results in activation of psychophysiological processes. This activation may then interfere with recovery processes (e.g., sleep) and can therefore contribute to the development of work-related chronic fatigue.

Cropley \& Zijlstra (2011), in their broad construct of work-related rumination, have differentiated between affective rumination and problem-solving pondering. According to Cropley \& Zijlstra, the main difference between these two forms of perseverative thinking about work lies in the amount of emotional response they evoke. When thinking about workrelated issues results in a negative emotional response (e.g., frustration, annoyance, feeling emotionally exhausted), people are said to be engaging in affective rumination. Often the focus of this kind of thinking is not about solving issues but is more akin to rumination found in the clinical literature whereby the person is caught up in a negative emotional response loop, unable to arrest the process. In contrast, problem-solving pondering is focused on finding solutions to work-related problems, or planning how to tackle an uncompleted task at work the next day, and the emotional response is not evoked. Problem-solving pondering could even be a positive experience, especially if a solution is arrived at. Problem-solving 
pondering about work-related issues may be goal directed (e.g., thinking about how to complete an unfinished task or considering how one might improve one's performance at work), which means that people who ponder work-related issues in non-work time may 'switch-off' once the goal has been achieved (Martin \& Tesser, 1996). According to Cropley $\&$ Zijlstra, no such relief presents itself for people who engage in affective rumination because it is not characterised as goal directed; therefore, the rumination process continues unabated. It is this continued activation which is purported to interfere with recovery because psychophysiological arousal remains high, meaning that recovery processes requiring downregulation (e.g., sleep) are negatively impacted.

Affective rumination and problem-solving pondering are closely linked and share significant positive variance; however, there is also a very important difference between them which was highlighted in a recent study. Querstret and Cropley (2012) conducted a large $(\mathrm{N}=719)$ cross-sectional study exploring the relationship between different forms of workrelated rumination and work-related fatigue. They found that affective rumination was a significant predictor both of acute (end-of-day) work-related fatigue, and of chronic (longterm) work-related fatigue, whereas problem-solving pondering was not. In fact, their results appeared to suggest that problem-solving pondering may confer some benefits in the context of recovery from work. Querstret and Cropley proposed that it is not thinking about work outside of work per se that is the problem, but rather the type of thinking and subsequent level of emotional activation that is important.

We believe there is a potentially complex relationship between work-related fatigue and work-related rumination in terms of causation. Querstret and Cropley (2012) suggested that affective rumination may be implicated in a causal model for fatigue, maintaining psychophysiological arousal because of the emotional content of the process; however, we think that these two constructs may be involved in a cyclical acceleration model. Specifically, while affective rumination may interfere with recovery processes by extending work-related 
demands into non-work time resulting in fatigue (e.g., by interfering with sleep); individuals who are fatigued may in turn ruminate more frequently. For example, if an individual is fatigued, this may impact on their concentration levels and productivity at work, in turn resulting in deadlines being missed which could foster work-related rumination with regards to incomplete tasks. Individuals who are fatigued may also experience reduced emotional resilience which could increase irritation and other negative affective constructs. These factors combined could mean that increased levels of work-related fatigue actually result in increased levels of work-related rumination, which in turn could interfere with recovery processes (e.g., sleep) resulting in further increases in work-related fatigue.

Given our proposition regarding the cyclical acceleration relationship between fatigue and rumination; in the current study, we were interested in examining the impact of a one-day workplace CBT-based workshop on self-reported levels of affective work-related rumination and work-related fatigue. We focussed on affective rumination because previous research suggested it may be more damaging to recovery than other forms of work-related rumination (see, Querstret \& Cropley, 2012). Furthermore, as the study is set in the context of the recovery from work literature and as sleep is undoubtedly one of our most important restorative processes (Stewart, Abbey, Meana, \& Boydell, 1998; Singh, Clements, \& Fiatarone, 1997; O'Connor, \& Youngstedt, 1995), we were also interested in the effect of the intervention on sleep quality.

\section{What is CBT?}

Cognitive Behaviour Therapy refers to a class of interventions sharing the basic premise that psychological distress (and mental disorder) is maintained by cognitive factors which interact with behaviour to perseverate symptoms (Hofmann, Asnaani, Vonk, Sawyer, \& fang, 2012). This treatment approach was pioneered by Beck (1970) and Ellis (1962) and the core premise purports that maladaptive cognitions contribute to the maintenance of emotional distress and associated behavioural problems. According to Beck, maladaptive 
cognitions include general beliefs (or 'schemas') about the world, the self, and the future; and these schemas give rise to specific and automatic (maladaptive or unhelpful) thoughts in particular situations. Effectively, these schemas shape the individuals view of the world and of themselves in it. CBT interventions aim to equip individuals with the skills to identify and change these maladaptive cognitions (e.g., depressive rumination, worry), thereby reducing associated psychological distress and alleviating psychological disorder (e.g., depression, anxiety) (Beck, 1970).

\section{CBT interventions and recovery from work}

CBT interventions for occupational stress are designed to educate employees about the role of their thoughts and emotions in managing stressful situations and to provide them with the skills to modify their thoughts to facilitate adaptive coping. For example, employees are taught to: a) become aware of negative thoughts or irrational beliefs; b) to challenge these negative thoughts or irrational beliefs; and c) to substitute positive or rational thoughts and beliefs which will (hopefully) become embedded over time (Bellarosa \& Chen, 1997). A number of meta-analytic reviews have examined the impact of CBT interventions for the reduction of occupational stress; and the majority of results converged to support the contention that CBT interventions were more effective in comparison to other intervention types (e.g., organisation-focused therapies), especially when the CBT intervention focused on psycho-social outcomes in employees (e.g., perceived stress, anxiety, depression, and burnout) (Richardson \& Rothstein, 2008; van der Klink, Blonk, Schene, \& van Dijk, 2001). In these meta-analytic reviews, the majority of included studies reported moderate to large effect sizes in the short-term; however, there was evidence that the effect of the interventions reduced over time (see e.g., Richardson \& Rothstein, 2008; van der Klink, et al., 2001), and more research regarding the long-term effects of CBT for occupational stress is needed (Hofmann, et al., 2012). 
To date, no one has assessed a CBT-based intervention for its effects on work-related rumination; however, results from a recent the systematic review suggest that CBT-based interventions have been shown to be effective in the reduction of depressive rumination and worry (for review, see Querstret \& Cropley, 2013), which are associated forms of perseverative cognition (Brosschot, et al., 2006). Cognitive Behaviour Therapy interventions may be effective in the reduction of work-related rumination because methods utilised in CBT may be very helpful in arresting the process of rumination. Specifically, understanding the link between thoughts, emotions and behaviour and working to identify, challenge and change maladaptive thinking patterns about work, may greatly aid people's abilities to disengage from thinking about work when not at work.

Studies have also shown that CBT interventions may be beneficial for individuals with sleep problems (e.g., insomnia). For example, a recent meta-analysis examined the efficacy of CBT interventions on both subjective (e.g., self-report) and objective (e.g., polysomnography) sleep parameters in comparison to control groups for individuals with insomnia (Okajima, Komada, \& Inoue, 2011). Effect sizes for the included studies ranged from moderate to large and the findings from this meta-analysis are consistent with results from other meta-analyses (see, e.g., Irwin, Cole, \& Nicassio, 2006; Montgomery \& Dennis, 2004); however, effects do appear to fade relatively quickly and some authors have asserted the need for 'booster' sessions of CBT in order for the short-term effects to be maintained over time (e.g., past 6 months; Montgomery \& Dennis, 2004).

\section{Hypotheses}

Evidence supporting the efficacy of CBT-based interventions for the reduction of work-related psychological complaints has been found in a number of reviews (see, e.g., van der Klink, et al., 2001; Richardson \& Rothstein, 2008; Hofmann, et al., 2012); and, as stated previously, CBT interventions have proven effective for the reduction of perseverative cognitions, for example, depressive rumination and worry (for review, see Querstret \& 
Cropley, 2013), and also for the improvement of sleep (for review, see Okajima, et al., 2011). Furthermore, as previous research has shown work-related rumination, specifically affective work-related rumination, is associated with increased levels of chronic work-related fatigue (Querstret \& Cropley, 2012); the impact of the CBT intervention on chronic work-related fatigue was also of interest. Therefore, in comparison to control group participants, it was hypothesised that individuals who attended the CBT-based workshop would report...

...significantly lower levels of affective work-related rumination at follow-up (H1)

...significantly lower levels of chronic work-related fatigue at follow-up (H2)

...significantly higher levels of sleep quality at follow-up (H3)

\section{Methods}

\section{Ethical approval}

Ethical approval was granted by the Faculty of Arts \& Human Science ethics committee at the University of Surrey.

\section{Design}

This was a quasi-experimental longitudinal design. All study participants completed an online questionnaire at the same two time-points. Almost half of the sample $(\mathrm{N}=102)$ attended a one-day CBT-based workshop, they completed the online questionnaire as part of the pre-work for the workshop (T1=September), and were then followed-up 6 months postworkshop attendance (T2=March). Participants who did not receive the intervention $(\mathrm{N}=125)$ completed the online questionnaire at one time-point (T1=September) then were followed-up 6 months later (T2=March) to assess change in self-reported symptoms. The quasiexperimental nature of this study is borne of the fact that the majority of the participants attending the workshop came from the same organisation. Participants in the non-workshop group were approached via email as they had taken part in a previous cross-sectional study run by the University of Surrey (using different measures to those included in this study); therefore, group membership was not randomised in any way. 


\section{Sample and participants}

The sample was comprised of 227 working adults $(M=37 \% ; n=84)$ with an age range of 22-66 years $(\mathrm{M}=42.62, \mathrm{SD}=9.83)$. The majority of participants $(87.6 \% ; \mathrm{n}=199)$ worked full-time for a mean of $44.04(\mathrm{SD}=15.04)$ hours per week in jobs they had held for a mean of $6.23(\mathrm{SD}=6.71)$ years. One hundred and eighty six participants $(81.9 \%)$ were married or had a partner, 15 participants $(6.6 \%)$ were separated/divorced or widowed, and 26 participants (11.5\%) were single. One hundred and thirteen participants (49.8\%) reported having dependent children. One hundred and eighty three participants $(80.6 \%)$ worked a traditional 9am-5pm (Mon-Fri) pattern, with the remaining 44 participants (19.4\%) working shifts. Many industry sectors were represented in the sample with participants from legal representing $35.3 \%(n=80)$ of the sample, followed by police $(15.8 \% ; n=36)$, education $(14.9 \% ; \mathrm{n}=34)$, nursing $(12.4 \% ; \mathrm{n}=28)$, healthcare $(7.9 \% ; \mathrm{n}=18)$, administration $(4.4 \% ; \mathrm{n}$ $=10)$, and other $(9.3 \% ; \mathrm{n}=21)$. The majority of participants were University educated $(83.25 \% ; \mathrm{n}=189)$. Sample specifics for each of the study groups are presented in Table 1 .

\section{CBT-based workshop}

Overview. The CBT-based workshop assessed in this study was developed to be delivered within the context of the workplace. The work environment provides an ideal and practical location as it affords individuals the ability to draw on everyday examples of workplace situations and issues surrounding work-life balance (Millear, Liossis, Shochet, Biggs, \& Donald, 2008). Participants in the intervention group attended a one day CBT-based workshop which was carried out at their place of work. Each workshop accommodated between 10-20 participants and was facilitated and presented by the same clinical psychologist with more than 10 years' experience in delivering CBT-based interventions. The full-day interactive workshop was designed to enable participants to understand: the cognitive behavioural model of emotions; the impact of maladaptive thinking in a work context and how to change this thinking; the relationship between emotions, thinking and 
behaviour; and to identify personal strengths when dealing with pressure at work. Participants who attended the workshop took part in group discussions, written and small group exercises, and developed individual practical plans for implementation after workshop completion. Before the workshop, participants received a preparation document which asked them to think about situations where they have performed well under pressure, as well as situations where they have not performed well under pressure. This was to allow them time to think about meaningful situations they would like to discuss during the workshop. The workshop focused on three main themes common in CBT interventions: 1) thinking about thinking; 2) the impact of cognitive perceptions (cognitive distortions or 'mind traps'); and 3) the role of behaviour.

Workshop details. During the first hour and a half of the workshop, a psychoeducational session focussed on research findings with regards to the impact of stress on health and wellbeing; the potential effects of stress on individuals and organisations; and the changing nature of stressors (i.e., increased levels of psychological stress). Next the focus moved to helping the participants to understand the difference between pressures (triggers) and stress (response). The physiological process associated with stress and the impact that this can have on health and wellbeing was discussed. Participants were then given the opportunity during small group exercises to look at their own top three work stressors. This was followed by a large group discussion which illustrated that even though there is constant pressure in society, not everybody reacts with the same stress response.

After a 15 minute break the focus of the workshop moved onto cognitive awareness, or thinking about thinking. This section introduced the model used in CBT and highlighted the relationship between thoughts, emotions and behaviour. The framework of the workshop was primarily informed by the Cognitive Model of emotions which suggests that people's reactions and emotions are influenced by their perception of a situation rather than by the situation itself (Beck, 1964; Ellis, 1962). It is therefore important to look not only at a 
person's initial thoughts in high pressure situations, but also to uncover the semi-conscious processes which are embedded slightly deeper in the psyche (Beck, 1995). The impact of thinking was illustrated by various concrete examples and was also explained by illustrating the basic neuropsychological principles of how thoughts affect emotions. After the theoretical discussion, participants moved back into their small groups to practice a basic thought awareness exercise (called the $\mathrm{ABC}$-exercise) looking at specific events from their own lives. Ellis (1977) proposed the ABC model which explains the relationship between thinking and emotion: A=Activating Event; $\mathrm{B}=$ Beliefs and thoughts; $\mathrm{C}=$ Emotional and behavioural consequences. What this model enables individuals to understand is that emotional distress and problematic behaviour $(\mathrm{C})$ are consequences, not of the events themselves (A), but of the individual's negative inferences and evaluations of the events (B). Thought awareness exercises are a very important component in identifying and changing negative thinking patterns such as rumination. Participants were encouraged to consider work-related events and how their beliefs and thoughts affected their emotional responses and behaviour.

Next, a theoretical discussion focused on the impact of cognitive perceptions - or cognitive thought distortions - called 'mind-traps' (Beck, Rush, Shaw \& Emery, 1979). There was a specific focus on how past experiences can wrongly affect our thinking styles, how people tend to see what they expect to see; and also how resistant perceptions can be to change unless a major effort is made to spot and change them. Next, the mind-traps (e.g., catastrophic thinking, mind-reading, overgeneralisation and emotional reasoning) were discussed one by one, as well as the impact of these thinking styles on people's reactions and emotions. Participants then returned to their $\mathrm{ABC}$ exercises to see if they could identify any specific mind-traps they consistently applied to work-related situations or events. This exercise helped participants to realise how often they distort reality and how much mind-traps were affecting their emotions and behaviour in their own lives. The next exercise was a basic thought restructuring exercise helping participants to challenge and change any negative 
intrusive thoughts and mind-traps; a very important skill in changing perseverative thinking patterns such as rumination. The impact of choosing to change was a central theme throughout this section and participants had the opportunity to assess their own attitudes towards pressure and stress.

The final section focused on the importance of behaviour and the link between emotions, thoughts and behaviours. Two different types of work-related behaviours were discussed: performance behaviours and recovery behaviours. Performance behaviours refer to behaviours such as time-management, managing working hours, communication under pressure, building relationships with others and taking time out to think about thinking. Recovery behaviours included behaviours which help people to recover from stress and manage a decent work-life balance. Content and discussion focused on the impact of sleep, exercise, diet and social interaction on health and wellbeing. Practical exercises included reviewing their own performance and recovery behaviours and identifying those they considered most personally important with a view to making changes; e.g., managing working hours more effectively, making more time for quality sleep, changing diet, engaging in more exercise. Group discussion focussed on helping participants to understand how maladaptive cognitions could have an impact on performance and recovery behaviours.

During the closing session of the workshop, attendees developed individual practical plans for implementation after workshop completion. Their plans emphasised the areas they felt they would like to focus on, in the context of the workshop themes; and it was hoped that development of a personal plan would encourage further engagement with the content of the workshop in the weeks and months following workshop completion.

\section{Measures}

Work-Related Rumination. The Work-Related Rumination Questionnaire (Cropley, Michalianou, Pravettoni, \& Millward, 2012) is a self-report measure designed to measure a 
proposed three-factor model of perseverative thinking about work. The affective rumination subscale - comprised of five items - was analysed in this study. Included in the affective rumination subscale are items such as, "Are you annoyed by thinking about work-related issues when not at work?" and "Do you become tense when you think about work-related issues during your free time?". Items are responded to against a 5-point Likert scale ranging from $1=$ Very seldom/never to $5=$ Very often/always, and each subscale yields a total score which ranges from 5 to 25 , with higher scores representing higher levels of the factor. In a previous study, the Cronbach's alpha for affective rumination was .90 (Querstret \& Cropley, 2012); and in this study, Cronbach's alpha for affective rumination were: $\mathrm{T} 1=.85 ; \mathrm{T} 2=.87$.

Work-related fatigue. The Occupational Fatigue Exhaustion Recovery scale (OFER) is a 15-item measure that has been validated in several studies as a measure of work-related fatigue (Winwood, et al., 2007; Winwood, et al., 2006; Winwood, Winefield, Dawson, Lushington, 2005). We used the Chronic Fatigue (CF) subscale because we were interested in fatigue that is persistent/long-term. The CF subscale contains items that reflect the complexity of this construct as a mixture of mental, physical and emotional components, consistent with the observed and reported characteristics of persistent fatigue (Winwood et al., 2006). This subscale is comprised of five items. Typical items for the CF include subscale, "I often dread waking up to another day of my work"; "I often wonder how long I can keep going at my work"; and "Too much is expected of me in my work". Each item is responded to on a seven point Likert scale ranging from $0=$ "Completely disagree" to 6="Completely agree". Each subscale yields a total score that ranges from 0-100 (score $=[\Sigma$ (item scores) /30] x 100). The Cronbach's alpha for CF has been reported in a previous study as .91 (Querstret \& Cropley, 2012); and in this study as: T1=.91, T2=.87.

Sleep Quality. The Pittsburgh Sleep Quality Index (PSQI) is a well validated questionnaire comprised of 19 items assessing sleep quality and disturbances over a onemonth interval (Buysse, Reynolds III, Monk, Berman, \& Kupfer, 1988). These 19 items 
result in seven component scores (subjective sleep quality, sleep latency, sleep duration, habitual sleep efficiency, sleep disturbances, use of sleep medication, and daytime dysfunction) which are summed together to yield a global PSQI score, ranging from 0 to 21. Higher scores reflect poorer sleep quality (Buysse, et al., 1988). The Cronbach's alpha for this scale has been reported in a previous study to be 0.83 (Buysse, et al., 1988; Carpenter \& Andrykowski, 1988); and in this study as: $\mathrm{T} 1=.70 . \mathrm{T} 2=.74$.

Control variables. Single items were included in the survey for gender ( $1=$ female; 2=male), age, educational level ( $1=$ =University educated; $2=$ Not university educated); work pattern (1=9am-5pm [Mon-Fri], 2=shift work); work type (1=full-time, $2=$ =part-time $)$ and hours worked per week. The reason for including these control variables was because we did not randomise group membership; therefore, we wished to control for differences between the groups at baseline which may have had an impact on the results.

Furthermore, while this study was focussed on assessing the effectiveness of the workshop for changing levels of self-reported work-related rumination and work-related fatigue; we felt it was important to control for other measurable variables which theoretically, and on the basis of existing research, could also be influenced by the intervention and could covary with work-related rumination and/or work-related fatigue. For example, in the context of the effort-recovery theory (Meijman \& Mulder, 1998), increased job demands interfere with recovery processes by reducing the time available to the individual; and limited control at work can damage recovery because individuals may be required to continue expending effort at times when they require a break psychologically and physiologically. As such, both low control at work and high levels of demand at work can compromise opportunities for recovery and could potentially be related to work-related rumination and work-related fatigue.

Job control and job demands. Eleven items from the Job Content Questionnaire (JCQ; Karasek, Brisson, Kawakami, Houtman, Bongers, \& Amick, 1988) were used to 
measure perceived job demands (JD); and included items such as, "Do you have to work very fast?". Ten items from the JCQ were used to measure perceived job control (JC); and included items such as, "Do you have a choice in deciding HOW you do your work?". Each item was responded to on a 4-point Likert scale ranging from 1=Never/Almost never to 4=Often. For each of these scales, items are summed to yield a total score which ranges from 10 (JC) or 11 (JD) to 40 (JC) or 44 (JD), with high scores indicating high job demands, or high job control, respectively. Cronbach's alphas in a previous study were .78 (job demands) \& .76 (job control; Querstret \& Cropley, 2012). Cronbach's alphas in this study were: Job demands $\mathrm{T} 1=.77, \mathrm{~T} 2=.80 ;$ Job control $\mathrm{T} 1=.85, \mathrm{~T} 2=.87$.

\section{Results}

\section{Sub-sample demographics}

Table 1 shows all demographic details for the workshop and non-workshop groups.

\section{(Insert Table 1 about here)}

\section{Data analysis}

Correlation analysis. Means and standard deviations for the study variables can be viewed in Table 2; and correlations for the study variables can be viewed in Table 3. We reviewed the correlation table to check if our proposed control variables were correlated with each other and the dependent variables. Hours per week was significantly correlated with job demands; work pattern (1=9am-5pm [Mon-Fri], 2=shift work) was significantly correlated with job demands (T1) and job control; and education level (1=University educated; $2=$ Not university educated) was correlated with job demands, job control (T2) and affective rumination. Because of these significant correlations, these variables were controlled for in further analysis. Work type was not significantly correlated with any other control variables, 
nor to the dependent variables; therefore, work type was not included as a covariate in further analysis.

Analytic approach. Two stages of data analysis were conducted. Firstly, a multivariate analysis of covariance (MANCOVA) was carried out to assess the effect of the intervention on the dependent variables together. MANCOVA is an appropriate approach to use when dependent variables are correlated with each other (see Table 3) because it takes into account this shared variance when assessing the efficacy of the intervention. Secondly, a series of analysis of covariances (ANCOVAs) were conducted on each of the dependent variables to assess the effect of the intervention on them individually. Before conducting the main analyses, the data were tested for the presence of outliers and normality was assessed (Field, 2009). There were no multivariate outliers in the data and the data was normally distributed (assessed via review of histograms and absolute skew and kurtosis values; see Table 2). All analysis was conducted in SPSS version 21(IBM Corp, 2012).

(Insert Table 2 about here)

Multivariate Analysis of Covariance (MANCOVA) results. We entered the T2 scores as the dependent variables (affective rumination T2; chronic fatigue T2; sleep quality T2) and whether or not participants attended the CBT-based workshop (intervention) as the between-subjects variable. We included the following covariates in the analysis: T1 scores for each dependent variable, job control and job demands. We also included hours worked per week as a covariate because the workshop group reported a significantly higher number of hours worked per week at baseline than the non-workshop group $(F[1,225]=9.705$, $\mathrm{p}=.008$ ); work pattern, because the non-workshop group was comprised of people working both traditional (9am-5pm Mon-Fri) and non-traditional (shift work) patterns, whereas all participants in the workshop group worked a traditional pattern; and we included level of 
education because it was correlated with affective rumination (see Table 3). The assumption of equality of covariance matrices was satisfied, Box's $M=7.373, F=1.211, p=.30$; and the analysis showed a significant multivariate main effect for group, Wilks' $\lambda=.057, \mathrm{~F}(3$, 217) $=4.34, \mathrm{p}=.005, \mathrm{n}_{\mathrm{p}}{ }^{2}=.06$ (medium effect size; Cohen, 1988).

Analysis of Covariance (ANCOVA) results. In the next stage of the analysis, individual ANCOVA's were carried out to assess the effect of the intervention on each of the dependent variables. The homogeneity of variance assumption was satisfied for affective rumination and sleep quality because Levene's F test was non-significant (affective rumination $[\mathrm{F}(1,225)=1.83, \mathrm{p}=.18]$; sleep quality $[\mathrm{F}(1,225)=1.66, \mathrm{p}=.20])$; however, Levene's $\mathrm{F}$ test was violated for chronic fatigue $[\mathrm{F}(1,225)=5.28, \mathrm{p}=.02]$, suggesting that the variances between groups may be significantly different. However, Field (2009) suggests that the Levene's F test is not necessarily the best way to judge whether variances are unequal enough to cause problems; instead a useful double-check is to conduct a Hartley's F MAX, $_{\text {, or variance }}$ ratio, test. The variance ratio is calculated by dividing the largest group variance by the smallest group variance; and an appropriate ratio is anything below 2 (Field, 2009). The variance ratio for chronic fatigue was less than two (chronic fatigue $F_{M A X}=1.24$ ); therefore, homogeneity of variance has been assumed for all dependent variables.

For each ANCOVA analysis, T1 scores and demographic control variables (age, gender, children, work status, work pattern, hours worked per week, education level) were entered as covariates in the model. The correlation matrix (see Table 3) was then reviewed to ascertain to which of the ANCOVAs job demands and job control should be added as covariates. Job demands was correlated with affective rumination and chronic fatigue so it was entered as a covariate in the respective ANCOVA analyses. Job control was correlated with all of the dependent variables; therefore it was included in each of the ANCOVAs.

We found that attendance at the CBT-based workshop had a significant effect at follow-up on affective rumination $\left(\mathrm{F}[1,222]=3.352, \mathrm{p}=.03, \mathrm{\eta}_{\mathrm{p}}{ }^{2}=.02\right)$ and chronic fatigue $(\mathrm{F}[1$, 
$\left.223]=8.936, \mathrm{p}=.003, \mathrm{\eta}_{\mathrm{p}}{ }^{2}=.04\right)$; however, there was no significant effect on sleep quality $\left(\mathrm{F}[1,224]=2.047, \mathrm{p}=.06, \mathrm{\eta}_{\mathrm{p}}{ }^{2}=.01\right)$. Specifically, participants who attended the CBT-based workshop reported significantly lower levels of chronic fatigue and affective rumination at follow-up than participants who did not attend the workshop. According to Cohen's (1988) guidelines, partial eta squared $\left(\mathrm{\eta}_{\mathrm{p}}^{2}\right)$ values of $.01, .06$, and .14 constitute small, medium, and large effect sizes respectively; therefore, the effect sizes for affective rumination and chronic fatigue were small. Hypotheses 1 and 2 were supported and hypothesis 3 was not supported.

\section{(Insert Table 3 about here)}

Analysis of change in covariates. As a secondary check, we assessed whether or not the workshop attendees reported significant changes in job demands and job control from T1 to $\mathrm{T} 2$. We conducted paired samples t-tests on the split file data (split by intervention vs. no intervention) for each of these variables. We found that participants who attended the workshop reported significantly higher levels of job control at T2 $(\mathrm{t}[101]=-2.842, \mathrm{p}=.005)$ when compared to their levels at T1; however, there were no significant differences between $\mathrm{T} 1$ and $\mathrm{T} 2$ for workshop attendees in self-reported job demands $\mathrm{T} 2(\mathrm{t}[101]=-0.315, \mathrm{p}=.75)$. For the non-workshop attendees there were no significant differences between T1 and T2 for job demands $(\mathrm{t}[124]=-1.143, \mathrm{p}=.25)$ or job control $(\mathrm{t}[124]=-0.873, \mathrm{p}=.38)$.

\section{Discussion}

This longitudinal quasi-experimental study aimed to assess the efficacy of a CBTbased one-day workshop intervention delivered in a workplace setting for the reduction of affective work-related rumination and chronic fatigue and for the improvement of sleep quality. Two of our three hypotheses were supported. We found that individuals who attended the workshop reported significantly lower levels of chronic fatigue at follow-up and significantly less affective rumination, than individuals who did not attend the workshop; 
however, there were no differences between the groups in self-reported sleep quality at follow-up. It is important to note that the effect sizes for these differences were modest, and it would be interesting to examine in future research whether the beneficial effects of the intervention were sustained longer term.

It is interesting that we found a significant reduction for both chronic fatigue and affective rumination and this finding is consistent with our argument, outlined in the introduction, that these two constructs may be involved in a cyclical acceleration model with one feeding the other. Given the possibility of a potentially complex (and as yet untested) relationship between these variables, it may be difficult to disentangle specifically which construct this workshop has affected; however, the reduction in both of these constructs cannot be explained by a reduction in perceived job demands as workshop attendees reported no significant reduction in job demands from $\mathrm{T} 1$ to $\mathrm{T} 2$.

In line with the CBT model, one possibility is that participants were able to identify and challenge maladaptive cognitions (e.g., catastrophising, over-generalisation) in relation to their work and this may have positively influenced both performance (e.g., managing working hours more effectively) and recovery (e.g., improved sleep) behaviours, which in turn may have reduced perceived levels of chronic fatigue. For example, if an individual's pervading mind-trap is that of 'over-generalising', whereby the individual believes that a piece of work (e.g., a report) will not be well received by the organisation because their maladaptive cognition is that their work "is never good enough", their usual behavioural response may be procrastination (putting off doing the piece of work due to fear of failure). This procrastination may invariably result in compromised performance behaviours (e.g., working longer hours to complete the work at the last minute) and may also impact on recovery behaviours (e.g., loss of sleep due to stress and longer working hours). If, via attendance at the CBT-based workshop, the individual can learn to identify and challenge the maladaptive cognitions (e.g., my work is never good enough) associated with their propensity 
to 'over-generalise', they would then be in a position to manage their working hours more effectively (as they may not procrastinate to the same degree) and they would also be in a better position to ensure adequate recovery takes place (e.g., enough good quality sleep). This type of cognitive restructuring (detecting and changing dysfunctional thinking habits into more functional and realistic ways of thinking) is intrinsic to CBT-based programmes (Beck, et al., 1979). In line with the Cognitive Model of emotions (Beck, 1964; Ellis, 1962), workshop attendees may have been able to disengage their emotional response to a situation from the actual situation itself.

Related to the point above, a further possibility for the change in chronic fatigue and affective rumination is that participants who attended the workshop made an intentional and concerted effort to engage in more performance and recovery behaviours. Performance behaviours include aspects such as: time-management, managing working hours effectively, communicating under pressure, building relationships with others and taking time out to think about thinking. Recovery behaviours include behaviours that enable participants to manage a decent work-life balance and to recover from stress (e.g., sleep, diet, exercise). For example, workshop attendees may have made and implemented plans to be more effective at timemanagement, or may have developed a better sense of work-life balance with regards to ringfencing hours spent at work. Previous research has shown that employees who prefer to segment their work and home environments - that is, by establishing clear boundaries between the two - report higher levels of psychological detachment from work during nonwork time (Park, et al., 2011). Perhaps the workshop attendees in this study established a clearer distinction between their work and non-work environments - for example, by switching off PDA's, mobile phones, or not checking work email when at home - thereby affording themselves more space for recovery processes to take place.

Furthermore, during the workshop, participants were encouraged to consider which recovery behaviours were most important to them and also to reflect on how they spent their 
time during the working week; therefore, it is possible that participants actively worked to change one or more of their recovery behaviours. The intervention did not significantly affect self-reported sleep quality; therefore we cannot conclude that the reduction in reported workrelated fatigue was mediated by an improvement in sleep quality. However, the finding that the intervention did not have an effect on sleep quality may be an artefact of the time lag between initial intervention attendance and follow-up (6 months). Indeed, the effect of the intervention at follow-up on sleep quality only marginally missed significance $(\mathrm{p}=.06)$, therefore it is possible that the intervention did have a positive influence on sleep but that this effect faded over time. This would align with research findings suggesting that the effects of CBT interventions for sleep appear to fade relatively quickly (see, e.g., Okajima et al., 2012); and that 'booster' CBT sessions may be necessary in the longer term in order for the effects to be sustained (Montgomery \& Dennis, 2004). As expanded on in the limitations section (below), a study design in which more measurement periods were added would show whether the intervention had an effect in the short-term which faded over time.

Taking part in the workshop may also have reinforced effective relationship skills resulting in a more harmonious work environment. If individuals have more functional and enjoyable relationships with colleagues, this may mean an increased sense of wellbeing and satisfaction at work, leading to a decrease in one potential cause of affective rumination. While we did not gather any qualitative feedback from participants and did not ask specifically about interpersonal relationships at follow-up, a previous study assessing the efficacy of a workplace-based programme found that participants reported significant improvements in relationships not just at work, but also outside of work (e.g., with children and other family members; Millear et al., 2008). Participants in the study by Millear and colleagues suggested that the group format increased their enjoyment of the programme and enabled them to acquire relationship skills which they then used at work and at home. The programme in the Millear et al. study was delivered in multiple sessions over many weeks, 
whereas the intervention in the current study was over one full day; nevertheless, the participants in our study may have enjoyed the group format and discussions and this may have had a positive effect outside of work, thereby promoting recovery. This presents an interesting avenue for future research to explore.

A further possibility is that workshop participants felt more able to cope with the demands of their work via an increase in coping self-efficacy. Coping self-efficacy represents an individual's ability to manage difficult situations and it is closely related to an individual's persistence and tenacity in dealing with challenges and adversity (Kleinke, 1998; Moos, 2002; Seligman, 1990; Reivish \& Shatte, 2002). Even though we did not measure coping self-efficacy in the current study, we did measure perceived control at work which is a closely-related construct. Our finding that workshop attendees reported a significant increase in job control between $\mathrm{T} 1$ and $\mathrm{T} 2$ may support an increase in perceived coping self-efficacy. In the current study, it is possible that an increase in coping self-efficacy has afforded participants of the workshop some respite from affective rumination, less interference with recovery processes and a corresponding reduction in perceived work-related fatigue; however, this is speculative and represents an interesting avenue for future empirical work.

We have discussed rumination in the present study in terms of its negativity (i.e., its association with poor sleep and fatigue); however it is also possible that rumination could actually lead to an increase in positive affect. This is likely when the process of rumination leads to a successful outcome. For example, positive process-focussed rumination focuses on the process of how events occurred, 'How can I solve this problem', (How can I become more creative'). Indeed this type of thinking could be advantages in the occupational context (Cropley \& Zijlstra, 2011; Querstret \& Cropley, 2012). However, according to the model put forward by Martin and Tesser (1989), rumination typically hinders goal attainment. Further research is needed to explore the potential positive aspects of rumination. 
Theoretically, the effects of the workshop could be interpreted as follows. In line with the effort-recovery theory (Meijman \& Mulder, 1998) individuals who attended the workshop may have made efforts to discontinue taxing their systems by: engaging in more recovery behaviours outside of work (e.g., diet, exercise); disengaging from work-related thinking; and becoming more able to deal with the demands of their work whilst at work (e.g., better timemanagement, management of hours worked, and building better working relationships with others). And in the context of the conservation of resources theory (Hobfoll, 1998), workshop attendees may have increased their internal resources, for example, due to increased levels of coping self-efficacy. In concert with one another, it may be a combination of more effective recovery both at work and outside of work that explain the reduction in both affective rumination and chronic fatigue.

\section{Limitations}

It is useful to start with a consideration of the limitations of the study design because these limitations restricted our interpretation of the results. Firstly, as mentioned in the methods section for the study, this was a quasi-experimental design because the workshop and non-workshop groups were formed from convenience samples. As a result, there were differences in the groups at baseline; however, the groups were closely matched on age, gender, hours worked per week, number of years working in current role, and on percentage of the sample married and with children. Where possible, differences between the groups have been controlled for statistically in the analysis. Nevertheless, the majority of workshop attendees came from the same organisation and indeed the same occupational group (lawyers); therefore, it is possible that there is something specific to this occupational group, or organisational context, which fostered an ability to engage with the workshop and implement changes. Furthermore, it is possible that something unmeasured in this study, and unique to the organisation within which workshop participants worked, caused the observed changes in the dependent variables instead of attendance at the workshop. As such, the 
generalisability of the findings in this study to other occupational groups or organisational contexts needs to be tested through further empirical work. For example, it would be advantageous for the workshop and non-workshop groups to be drawn from the same occupational context and randomised to the different treatment groups. It would also be useful to test the effectiveness of the intervention in other occupational groups.

Another limitation lies in the lack of coherence between intervention design and measures employed. Whilst it is appropriate to assess change in work-related rumination, sleep and chronic fatigue - because theoretically, and on the basis of existing research, CBT interventions may have an effect on these measures (see, e.g., van der Klink, et al., 2001; Okajima, et al., 2011) - it was not possible to assess the mechanisms of change. This is predominantly because the workshop was designed by the organisation in isolation from the research team; and the timescales to design, test and launch the online assessment questionnaire did not enable detailed thinking with regards to assessing potential mechanisms of change appropriately. Therefore, some of the interpretation above (whilst based in theory and aligned with previous research findings) is speculative and further empirical work is needed.

Finally, the design of this study would be considerably strengthened if change was assessed more robustly; for example, before the intervention, immediately after the intervention, and then at three and six months post intervention. The six month time lag between workshop completion and follow-up (without any intervening assessment) increases the likelihood that something (unmeasured) other than the workshop may have caused the changes in the dependent variables. However, there were no significant changes in the organisation within which the workshop attendees worked over the six month period of the study. There is no doubt that measuring change over more points in time would be beneficial; but one of the challenges inherent in conducting research in real-life settings is that it is often not possible to negotiate 'ideal' or 'preferred' timelines. In this case, it was not possible to 
assess change in the participants between the two measurement points. Nevertheless, this quasi-experimental longitudinal study also confers a considerable strength because this research was conducted in a real world setting which increases its ecological validity. Furthermore, conducting studies within organisational settings is an effective way to build collaborative research relationships and, over time, as the organisation learns to trust your approach, more robustly designed research can be carried out.

\section{Implications for the real world}

Employers have a responsibility to address work-related health risks; and it is increasingly important that employers make use of evidence-based practices and interventions in support of their workplace health and safety agendas. The current study showed that a one-day CBT-based intervention may be effective in improving employees' recovery and wellbeing; therefore, organisations could consider integrating such an intervention into their occupational health programmes. However, participation in such programmes should be voluntary. If involvement in these types of programmes was mandated, employees could consider this an intrusion, violating their ability to segment their work life from their private life. Research has shown that such violations increase perceived stress and reduce job satisfaction (Kreiner, Hollensbe, \& Sheep, 2009); therefore, organisations need to balance their desire to support their employees' health against the need to protect their employees' sense of work-life balance.

Traditional workplace stress management interventions do not focus on the impact of maladaptive cognitions for the maintenance of the response to stress; however, by acknowledging that different individuals experience the same environment (with the same inherent stressors) in very different ways, and by focussing on the helping individuals to understand the part their own cognitions play in their experience of work stress, interventions can essentially be tailored more effectively for different individuals. Developing stress management interventions which have a greater emphasis on intra-personal factors has 
intuitive appeal as employees will have very different and divergent motivations, learning styles and personal schemas through which they view the world. In the current study, while the intervention was situated within a traditional stress management training (SMT) content framework (e.g., understanding stress and its consequences), the format of the intervention was very much CBT-based, focussing on intra-personal factors which determine an individual's experience of stress (maladaptive cognitions and their interaction with performance and recovery behaviours). Helping participants to understand how their own maladaptive cognitions contribute to their experience of stress; and providing them with the tools to challenge and change those cognitions, personalises their experience of what is essentially a group-based intervention. Perhaps the success of the current workshop could be attributed to its multi-faceted coverage of a complex area, enabling attendees to engage with those areas which are most personally resonant.

\section{Conclusions}

Notwithstanding the limitations inherent in a quasi-experimental design, this study provides initial support for the use of a short (e.g., one day) CBT-based workshop delivered in a workplace environment for the reduction of work-related fatigue and rumination. 


\section{References}

Aaron, L.A., \& Buchwald, D. (2001). A review of the evidence for overlap among unexplained clinical conditions. Annals of Internal Medicine, 134, 868-881.

Akerstedt, T. (2006). Psychosocial stress and impaired sleep. Scandinavian Journal of Work Environment \& Health, 32, 493-501. DOI:10.5271/sjweh.1054.

Akerstedt, T., Fredlund, P., Gillberg, M., \& Jansson, B. (2002). Work Load and Work Hours in Relation to Disturbed Sleep and Fatigue in a Large Representative Sample. Journal of Psychosomatic Research, 53(1), 585-588.

Akerstedt, T., Knutsson, A., Westerholm, P., Theorell, T., Alfredsson, L., \& Kecklund, G. (2004). Mental Fatigue, Work and Sleep. Journal of Psychosomatic Research, 57(5), 427-433.

Baker, D.G., Mendenhall, C.L., Simbartl, L.A., Magan, L.K., \& Steinberg, J.L. (1997). Relationship between posttraumatic stress disorder and self-reported physical symptoms in Persian Gulf War veterans. Archives of Internal Medicine, 157, 20762078.

Beck, A.T. (1964). Thinking and depression: II. Theory and therapy. Archives of General Psychiatry, 10, 561-571.

Beck, A.T. (1970). Cognitive therapy: Nature and relation to behaviour therapy. Behavior Therapy, 1, 184-200.

Beck, A.T., Rush, A.J., Shaw, B.F., \& Emery, G. (1979). Cognitive therapy of depression. New York: Guilford Press.

Beck, J.S. (1995). Cognitive therapy: Basics and beyond. New York, NY: Guildford Press.

Bellarosa, C., \& Chen, P.Y. (1997). The effectiveness and practicality of occupational stress management interventions: A survey of subject matter expert opinions. Journal of Occupational Health Psychology, 2, 247-262. 
Berset, M., Elfering, A., Luthy, S., Luthi, S., Semmer, N. K. (2010). Work Stressors and Impaired Sleep: Rumination as a Mediator. Stress and Health, accessed 9/07/10 http://onlinelibrary.wiley.com/doi/10.1002/smi.1337/pdf

Brosschot, J. F., Gerin, W., \& Thayer, J. F. (2006). The Perseverative Cognition Hypothesis: A Review of Worry, Prolonged Stress-Related Physiological Activation and Health. Journal of Psychosomatic Research, 60(2), 113-124.

Burgard, S.A., \& Ailshire, J.A. (2009). Putting work to bed: Stressful experiences on the job and sleep quality. Journal of Health and Social Behaviour, 50, 476-492. DOI:10.1177/002214650905000407.

Bultmann, U., Kant, I.J., Kasl, S.V., Schroer, K.A., Swaen, G.M., \& van den Brandt, P.A. (2002). Lifestyle factors as risk factors for fatigue and psychological distress in the working population: prospective results from the Maastricht Cohort Study. Journal of Occupational and Environmental Medicine, 44, 116-124.

Bultmann, U., Kant, I., van Amelsvoort, L.G., van den Brandt, P.A., \& Kasl, S.V. (2001). Differences in Fatigue and Psychological Distress across Occupations: Results from the Maastricht Cohort Study of fatigue at work. Journal of Occupational and Environmental Medicine, 43(11), 979-983.

Buysse, D. J., Reynolds III, C. F., Monk, T. H., Berman, S. R., \& Kupfer, D. J. (1988). The Pittsburgh Sleep Quality Index: A New Instrument for Psychiatric Practice and Research. Psychiatry Research, 28(2), 193-213.

Carpenter, J. S., \& Andrykowski, M. A. (1998). Psychometric Evaluation of the Pittsburgh Sleep Quality Index. Journal of Psychosomatic Research, 45(1), 5-13.

Chen, M. K. (1986). The Epidemiology of self-perceived Fatigue among Adults. Preventive Medicine, 15(1), 74-81.

Cohen, J. (1988). Statistical Power Analysis for the Behavioral Sciences (2nd ed.). Lawrence Erlbaum Associates. 
Cropley, M., Dijk, D., \& Stanley, N. (2006). Job strain, Work Rumination, and Sleep in School Teachers. European Journal of Work and Organisational Psychology, 15(2), 181-196.

Cropley, M., Michalianou, G. Pravettoni, G., \& Millward, L. (2012). The relation of post work ruminative thinking with eating behaviour. Stress and Health, 28(1), 23-30.

Cropley, M., \& Millward, L. J. (2009). How do Individuals 'switch-off' from Work during Leisure? A Qualitative Description of the Unwinding Process in High and Low Ruminators. Leisure Studies, 28(3), 333-347.

Cropley, M. \& Zijlstra, F. R. H. (2011). Work and Rumination. In Langan-Fox, J \& Cooper, C.L. (Eds). Handbook of Stress in the Occupations. Edward Elgar Publishing Ltd., U.K.

De Bloom, J., Geurts, S.A.E., Taris, T.W., Sonnentag, S., de Weerth, C., \& Kompier, M.A.J. (2010). Effects of vacation from work on health and wellbeing: Lots of fun, quickly gone. Work \& Stress, 24, 196-216. DOI:10.1080/02678373.2010.493385.

De Bloom, J., Kompier, M., Geurts, S., de Weerth, C., Taris, T., \& Sonnentag, S. (2009). Do we recover from vacation? Meta-analysis of vacation effects on health and wellbeing. Journal of Occupational Health Psychology, 51, 13-25. DOI:10.1539/joh.K8004.

De Lange, A.H., Kompier, M.A.J., Taris, T.W., Geurts, S.A.E., Beckers, D.G.J., Houtman, I.L.D., \& Bongers, P.M. (2009). A hard day's night: A longitudinal study on the relationships among job demands and job control, sleep quality and fatigue. Journal of Sleep Research, 18, 374-383. DOI:10.1111/j.1365-2869.2009.00735.x.

Demerouti, E., Bakker, A.B., Geurts, S.A.E., \& Taris, T.W. (2009). Daily recovery from work-related effort during non-work time. In S. Sonnentag, P.L. Perrewe, \& D.C. Ganster (Eds.), Research in occupational stress and well being: Current perspectives on job-stress recovery (Vol. 7, pp. 85-123). Bingley, UK: JAI Press. 
Dinges, D.F., Pack, F., Williams, K., Gillen, K.A., Powell, J.W., Ott, G.E., Aptowicz, C., \& Powell, J.W. (1997). Cumulative Sleepiness, Mood Disturbance, and Psychomotor Vigilance Performance Decrements during a week of Sleep Restricted to 4-5 Hours per Night. Sleep, 20, 267-277.

Eden, D. (2001). Vacations and other respites: Studying stress on and off the job. In C.L.

Cooper \& I.T. Robertson (Eds.), International review of industrial and organizational psychology (Vol. 16, pp. 121-146). Chichester, England: Wiley.

Ellis, A. (1962). Reason and emotion in psychotherapy. New York, NY: Lyle Stuart.

Ellis, A. (1977). The basic clinical theory of rational-emotive therapy. In A. Ellis \& R.E. Grieger (Eds.), Handbook of Rational-Emotive Therapy (pp. 3-34). New York: Springer.

Etzion, D. (2003). Annual vacation: Duration of relief from job stressors and burnout. Anxiety, Stress, and Coping, 16, 213-226. DOI; 10.1080/1061580021000069425.

Felstead, A., Gallie, D., \& Green, F. (2002). Work skills in Britain 1986-2001. Nottingham: DfES Publications.

Field, A. (2009). Discovering Statistics Using SPSS (3rd ed.). London: Sage Publications Ltd. Flaxman, P.E., Bond, F.W., \& Livheim, F. (2013). The Mindful and Effective Employee: An Acceptance and Commitment Therapy Training Manual for Improving Wellbeing and Performance. Oakland, C.A.: New Harbinger Publications, Inc.

Flaxman, P.E., Menard, J., Bond, F.W., \& Kinman, G. (2012). Academics' Experiences of a Respite From Work: Effects of Self-Critical Perfectionism and Perseverative Cognition on Postrespite Wellbeing. Journal of Applied Psychology, 97(4), 854-865. DOI: $10.1037 / \mathrm{a} 0028055$. 
Fritz, C., \& Sonnentag, S. (2006). Recovery, Wellbeing and Performance-Related Outcomes: The Role of Work Load and Vacation Experiences. Journal of Applied Psychology, 91, 936-945.

Fritz, C., Sonnentag, S., Spector, P.E., \& McInroe, J.A. (2010). The Weekend Matters: Relationships between Stress Recovery and Affective Experiences. Journal of Organisational Behaviour, 31(8), 1137-1162.

Gallie, D., White, M., Cheng, Y. \& Tomlinson, M. (1998). Restructuring the Employment Relationship. OUP: Oxford.

Geiger-Brown, J., Trinkoff, A., \& Rogers, V.E. (2011). The impact of work schedules, home, and work demands on self-reported sleep in registered nurses. Journal of Occupational and Environmental Medicine, 53, 303-307.

DOI:10.1097/JOM.0b013e31820c3f87.

Geurts, S.A.E., \& Sonnentag, S. (2006). Recovery as an explanatory mechanism in the relation between acute stress reactions and chronic health impairment. Scandinavian Journal of Work and Environmental Health, 32(6), 482-492.

Groeger, J.A., Zijlstra, F.R.H., \& Dijk, D.J. (2004). Sleep quantity, sleep difficulties and their perceived consequences in a representative sample of some two thousand British adults. Journal of Sleep Research, 13, 359-371.

Harma, M., Kompier, M.A.J. \& Vahtera, J. (2006). Work-related stress and health-risks, mechanisms and countermeasures. Scandinavian Journal of Work and Environmental Health, 32, 413-419.

Harrison, Y. \& Horne, J.A. (1999). One Night of Sleep loss impairs Innovative Thinking and Flexible Decision Making. Organisational Behaviour and Human Decision Processes, 78(2), 128-145.

Hazlett, R. L., \& Haynes, S. N. (1992). Fibromyalgia: A time-series Analysis of the Stress or Physical Symptom Association. Journal of Behavioural Medicine, 15(6), 541-558. 
Hobfoll, S. E. (1998). Stress, culture, and community: The psychology and physiology of stress. New York: Plenum Press.

Hobfoll, S.E. \& Shirom, A. (1993), 'Stress and burnout in the workplace: conservation of resources', in R.T. Golembiewski (Ed.), Handbook of Organizational Behavior (pp. 41-60). New York: M. Dekker.

Hofmann, S.G., Asnaani, A., Vonk, I.J.J., Sawyer, A.T., \& Fang, A. (2012). The Efficacy of Cognitive Behavioral Therapy: A Review of Meta-analyses. Cognitive Therapy Research, 36, 427-440. DOI: 10.1007/s10608-012-9476-1.

Houtman, I. L. D. (1997). Trends in Work and Health. Amsterdam: NIA/TNO.

IBM Corp (2012). IBM SPSS Statistics for Windows, Version 21.0. Armonk, NY: IBM Corp.

Irwin, M.R., Cole, J.C., \& Nicassio, P.M. (2006). Comparative meta-analysis of behavioral interventions for insomnia and their efficacy in middle-aged adults and in older adults 55 years of age. Health Psychology, 25, 3-14.

Kantermann, T., Juda, M., Vetter, C., \& Roenneberg, T. (2010). Shift-Work Research: Where do we Stand, Where should we go? Sleep and Biological Rhythms, 8, 95-105.

Karasek, R., Brisson, C., Kawakami, N., Houtman, I., Bongers, P., \& Amick, B. (1988). The Job Content Questionnaire (JCQ): An Instrument for Internationally Comparative Assessments of Psychosocial Job Characteristics. Journal of Occupational Health Psychology, 3(4), 322-355.

Karni, A., \& Sagi, D. (1993). The Time Course of Learning a Visual Skill. Nature, 365, 250252.

Kinnunen, U., Feldt, T., Siltaloppi, M., Sonnentag, S. (2011). Job demands-resources model in the context of recovery: Testing recovery experiences as mediators. European Journal of Work and Organizational Psychology, 20(6), 805-832.

Kleinke, C.L. (1998). Coping with life challenges (2nd ed.). Pacific Grove, CA: Brooks/Cole Publishing Company. 
Kreiner, G.E., Hollensbe, E.C., \& Sheep, M.L. (2009). Balancing borders and bridges: Negotiating the workhome interface via boundary work tactics. Academy of Management Journal, 52, 704-730.

Kunert, K., King, L., \& Kolkhorst, F. W. (2007). Fatigue and Sleep Quality in Nurses. Journal of Psychosocial Nursing, 45(8), 31-37.

Lauber, J.K., \& Kayten, P.J. (1988). Sleepiness, Circadian Dysrhythmia, and Fatigue in Transportation System Accidents. Sleep, 11, 503-12.

Linton, S.J. (2004). Does Work Stress Predict Insomnia? A Prospective Study. British Journal of Health Psychology, 9, 127-136.

Loge, J. H., Ekeberg, O., \& Kaasa, S. (1998). Fatigue in the General Norwegian Population: Normative Data and Associations. Journal of Psychosomatic Research, 45(1), 53-65. Lyubomirsky, S., Caldwell, N. D., \& Nolen-Hoeksema, S. (1998). Effects of Ruminative and Distracting Responses to Depressed Mood on Retrieval of Autobiographical Memories. Journal of Personality and Social Psychology, 75(1), 166-177.

Lyubomirsky, S., Kasri, F., \& Zehm, K. (2003). Dysphoric Rumination Impairs Concentration on Academic Tasks. Cognitive Therapy and Research, 27(3), 309-330.

Lyznicki, J. M., Doege, T. C., Davis, R. M., \& Williams, M. A. (1998). Sleepiness, Driving, and Motor Vehicle Crashes. Journal of the American Medical Association, 279(23), 1908-1913.

Maslach, C., Schaufeli, W.B., \& Leiter, M.P. (2001). Job burnout. Annual Review of Psychology, 52, 397-422.

Martin, L.L., \& Tesser, A. (1989). Toward a motivational and structural theory of ruminative thought. In J. Uleman, \& J.A. Bargh (Eds), Unintended thought (pp.306-326). New York: Guildford Press. 
Meijman, T. F., \& Mulder, G. (1998). Psychological Aspects of Workload. In P. J. D. Drenth, H. Thierry, \& C. J. W. de (Eds.), Handbook of work and organizational psychology (Vol. 2, pp. 5-33). Hove, England: Psychology Press.

Meijman, T.F., Mulder, G., \& van Dormolen, M. (1992). Workload of driving examiners: A psychophysiological field study. In H. Kragt (Ed.), Enhancing industrial performances (pp. 245 - 260). London: Taylor \& Francis.

Mellings, T. M., \& Alden, L. E. (2000). Cognitive Processes in Social Anxiety: The Effects of Self-focus, Rumination and Anticipatory Processing. Behaviour Research and Therapy, 38(3), 243-257.

Millear, P.M., Liossis, P.L., Shochet, I.M., Biggs, H., \& Donald, M. (2008). Being on PAR: outcomes of a pilot study to improve mental health and wellbeing in the workplace with the Promoting Adult Resilience (PAR) programme. Behaviour Change, 25(4), 215-228.

Montgomery, P., \& Dennis, J. (2004). A systematic review of non-pharmacological therapies for sleep problems later in life. Sleep Medicine Reviews, 8, 47-62.

Moos, R.H. (2002). Life stressors, social resources, and coping skills in youth: Applications to adolescents with chronic disorders. Journal of Adolescent Health, 30(4 Suppl), 2229.

Nylen, L., Melin, B., \& Laflamme, L. (2007). Interference between Work and Outside-Work Demands Relative to Health: Unwinding Possibilities among Full-Time and PartTime Employees. International Journal of Behavioural Medicine, 14(4), 229-236.

O’Connor, P.J., \& Youngstedt, S.D. (1995). Influence of Exercise on Human Sleep. Exercise and Sport Sciences Reviews, 23, 105-134.

Okajima, I., Komada, Y., \& Inoue, Y. (2011). A meta-analysis on the treatment effectiveness of cognitive behavioral therapy for primary insomnia. Sleep and Biological Rhythms, 9, 24-34. DOI: j.1479-8425.2010.00481.x. 
Paoli, P. \& Merllie, D. (2001). Third European survey on working conditions 2000. Dublin: European Foundation for the Improvement of Working and Living Conditions. Online. Available http://www.eurofound.eu.int/publications/files/EF9721EN.pdf Park, Y., \& Fritz, C. \& Jex, S.M. (2011). Relationships Between Work-Home Segmentation and Psychological Detachment From Work: The Role of Communication Technology Use at Home. Journal of Occupational Health Psychology, 16(4), 457-467.

Porkka-Heiskanen, T., Kalinchuk, A., Alanko, L., Urrila, A., \& Stenberg, D. (2003). Adenosine, energy metabolism, and sleep. The Scientific World Journal, 3, 790-798. Pravettoni, G., Cropley, M., Leotta, S. N., \& Bagnara, S. (2007). The Differential Role of Mental rumination among Industrial and Knowledge Workers. Ergonomics, 50(11), 1931-1940.

Querstret, D., \& Cropley, M. (2012). Exploring the relationship between work-related rumination, sleep quality, and work-related fatigue. Journal of Occupational Health Psychology, 17(3), 341-353.

Querstret, D., \& Cropley, M. (2013). Assessing treatments used to reduce rumination and/or worry: a systematic review. Clinical Psychology Review, 33, 996-1009.

Reivich, K., \& Shatte', A. (2002). The resilience factor: Seven essential skills for overcoming life's inevitable obstacles. New York, NY: Broadway Books.

Richardson, K.M., \& Rothstein, H.R. (2008). Effects of occupational stress management intervention programmes: a meta-analysis. Journal of Occupational Health Psychology, 13(1), 69-93. DOI: 10.1037/1076-8998.13.1.69.

Rogers, N.L., Szuba, M.P., Staab, J.P., Evans, D.L. \& Dinges, D.F. (2001). Neuroimmunologic Aspects of Sleep and Sleep Loss. Seminars in Clinical Neuropsychiatry, 6, 295-307.

Sarason, I. G., Pierce, G. R., \& Sarason, B. R. (Eds.). (1996). Cognitive interference: Theories, Methods, and Findings. Hillsdale, NJ: Erlbaum, Inc. 
Schaufeli, W.B., \& Enzmann, D. (1998). The burnout companion to study and practice: A critical analysis. Washington, DC: Taylor \& Francis.

Schwartz, S., Anderson, W. M., Cole, S. R., Cornoni-Huntley, J., Hays, J.C., \& Blazer, D. (1999). Insomnia and Heart Disease: A Review of Epidemiologic Studies. Journal of Psychosomatic Research, 47(4), 313-333.

Seligman, M. E. P. (1990). Learned optimism. New York, NY: Knopf.

Siltaloppi, M., Kinnunen, U., \& Feldt, T. (2009). Recovery experiences as moderators between psychosocial work characteristics and occupational well-being. Work \& Stress, 23(4), 330-348.

Singh, N.A., Clements, K.M., \& Fiatarone, M.A. (1997). A Randomized Controlled Trial of the Effect of Exercise on Sleep. Sleep, 20, 95-101.

Sluiter, J.K., Frings-Dresen, M.H.W., Meijman, T.F., \& van der Beek, A.J. (2000). Reactivity and recovery from different types of work measured by chatecholamines and cortisol: a systematic literature overview. Occupational and Environmental Medicine, 57, $298-315$.

Sonnentag, S. (2011). Recovery from fatigue: The role of psychological detachment. In P.L. Ackerman (Ed.), Cognitive fatigue: Multidisciplinary perspectives on current research and future applications. Decade of Behaviour/Science conference, (pp. 253-272). Washington, US: American Psychological Association. DOI: 10.1037/12343-012. Sonnentag, S., \& Bayer, U-V. (2005). Switching Off Mentally: Predictors and Consequences of Psychological Detachment From Work During Off-Job Time. Journal of Occupational Health Psychology, 10(4), 393-414.

Sonnentag, S., \& Kruel, U. (2006). Psychological detachment from work during off-job time: The role of job stressors, job involvement, and recovery-related self-efficacy. European Journal of Work and Organisational Psychology, 15, 197-217. 
Stewart, D., Abbey, S., Meana, M., \& Boydell, K. M. (1998). What makes Women Tired? A Community Sample. Journal of Womens Health, 7, 69-76.

Strine, T.W., \& Chapman, D.P. (2005). Associations of Frequent Sleep Insufficiency with Health-Related Quality of Life and Health Behaviours. Sleep Medicine, 6, $23-27$.

Suadicani, P., Hein, H.O., \& Gyntelberg, F. (1993). Are Social Inequalities as Associated with the Risk of Ischemic-Heart-Disease a Result of Psychosocial WorkingConditions. Atherosclerosis, 101(2), 165-175.

Taylor, D.J., Mallory, L.J., Lichstein, K.L., Durrence, H.H., Riedel, B.W., \& Bush, A.J. (2007). Comorbidity of Chronic Insomnia with Medical Problems. Sleep, 30(2), 213218.

Van der Klink, J.J.L., Blonk, R.W.B., Schene, A.H., \& van Dijk, F.J.H. (2001). The benefits of interventions for work related stress. American Journal of Public Health, 91(2), 270-286.

Westman, M., \& Etzion, D. (2001). The impact of vacation and job stress on burnout and absenteeism. Psychology and Health, 16, 595-606. DOI:

10.1080/08870440108405529.

Williamson, A., Lombardi, D.A., Folkard, S., Stutts, J., Courtney, T.K., \& Connor, J., (2011). The Links between Fatigue and Safety. Accident Analysis and Prevention, 43(2), 498515.

Winwood, P. C., Bakker, A. B., \& Winefield, A. H. (2007). An Investigation of the Role of Non-work-time Behaviour in Buffering the Effects of Work Strain. Journal of Occupational and Environmental Medicine, 49(8), 862-871.

Winwood, P. C., Lushington, K., \& Winefield, A. H. (2006). Further Development and Validation of the Occupational Fatigue Exhaustion Recovery (OFER) scale. Journal of Occupational and Environmental Medicine, 48(4), 381-389. 
Winwood, P. C., Winefield, A. H., Dawson, D., \& Lushington, K. (2005). Development and Validation of a Scale to Measure Work-Related Fatigue and Recovery: the Occupational Fatigue Exhaustion Recovery scale (OFER). Journal of Occupational and Environmental Medicine, 47(6), 594-606.

Zijlstra, F.R.H., \& Sonnentag, S. (2006). After work is done: Psychological perspectives on recovery from work. European Journal of Work and Organisational Psychology, 15(2), 129-138. DOI: 10.1080/13594320500513855. 